\title{
Diving and the risk of barotrauma
}

\section{Erich W Russi}

Pulmonary Division, Department of Internal Medicine, University Hospital Zurich, Switzerland

Introductory article

Risk factors for pulmonary barotrauma in divers

K Tetzlaff, M Reuter, B Leplow, M Heller, E Bettinghausen

Study objectives. Pulmonary barotrauma (PBT) of ascent is a feared complication in compressed air diving. Although certain respiratory conditions are thought to increase the risk of suffering PBT and thus should preclude diving, in most cases of PBT, risk factors are described as not being present. The purpose of our study was to evaluate factors that possibly cause PBT. Design. We analyzed 15 consecutive cases of $P B T$ with respect to dive factors, clinical and radiologic features, and lung function. They were compared with 15 cases of decompression sickness without PBT, which appeared in the same period. Results. Clinical features of PBT were arterial gas embolism $(n=13)$, mediastinal emphysema $(n=1)$, and pneumothorax $(n=1)$. CT of the chest (performed in 12 cases) revealed subpleural emphysematous blebs in 5 cases that were not detected in preinjury and postinjury chest radiographs. A comparison of predive lung function between groups showed significantly lower midexpiratory flow rates at $50 \%$ and $25 \%$ of vital capacity in PBT patients $(p<0.05$ and $p<0.02$, respectively). Conclusions. These results indicate that divers with preexisting small lung cysts and/or end-expiratory flow limitation may be at risk of PBT. (Chest 1997;112:654-59)

Self-contained underwater breathing apparatus (SCUBA) diving has become a worldwide recreational sport activity. The open circuit SCUBA enables the diver to breathe high pressure gas from a cylinder through a regulator, which reduces the inhaled gas to ambient pressure and allows exhalation into the water. The rapidly changing ambient pressure under water may cause a variety of physiological alterations. Given the popularity of SCUBA diving and the number of diving accidents, physicians should be aware of the specific hazards and the medical conditions that may be encountered. ${ }^{1-3}$ I shall review these first, and then be encountered. ${ }^{1-3}$ I shall review these first, and then
consider the risks posed by pre-existing respiratory disorders, hence the importance of the introductory article.

Basic physics

Since most diving related complications are a consequence of the behavior of gases under changing conditions of pressure, it is appropriate to remember the two most relevant gas laws. Boyle's law states that at a constant temperature the volume of gas varies inversely with the pressure applied $\left(\mathrm{P}_{1} \mathrm{~V}_{1}=\mathrm{P}_{2} \mathrm{~V}_{2}\right)$. The physiological consequences of this law explain the pressure related diving diseases (i.e. barotrauma). Henry's law states that the amount of a given gas dissolved in a liquid is directly proportional to the partial pressure of that gas. This law provides the explanation of decompression sickness and nitrogen narcosis.
Diving related accidents

Drowning is reported to be the most common cause of death among divers, but arterial gas embolism as a complication of pulmonary barotrauma (PBT) ranks second, accounting for about $30 \%$ of recreational sCUBA diving fatalities. ${ }^{4}$ When symptoms occur because released bubbles are trapped in the non-pulmonary tissues of the diver as he ascends and is exposed to a reduction in environmental pressure (decompression), the condition is called decompression sickness (DCS). ${ }^{5}$

PULMONARY BAROTRAUMA

Divers breathing compressed gas while immersed at pressure are subject to the risk of pulmonary overinflation as pressure is reduced during ascent. According to Boyle's law a volume of gas at $30 \mathrm{~m}$ (4 bar) will double at $10 \mathrm{~m}$ ( 2 bar) and double again at the surface (1 bar). Normally, intrapulmonary and environmental pressures are equalised by exhalation during ascent. The mechanism underlying PBT is believed ing ascent. The mechanism und rying PBT is believed to be the consequence of the following events. Air,
unable to escape through the airways, ruptures into one unable to escape through the airways, ruptures into one
of three sites: the pulmonary capillaries causing arterial gas embolism, the perivascular sheaths causing mediastinal emphysema, or the pleural cavity causing pneumothorax.$^{67}$ Most critically, air rupturing into the pulmonary capillaries is carried to the left heart where its buoyancy in the upright ascending diver will direct it 


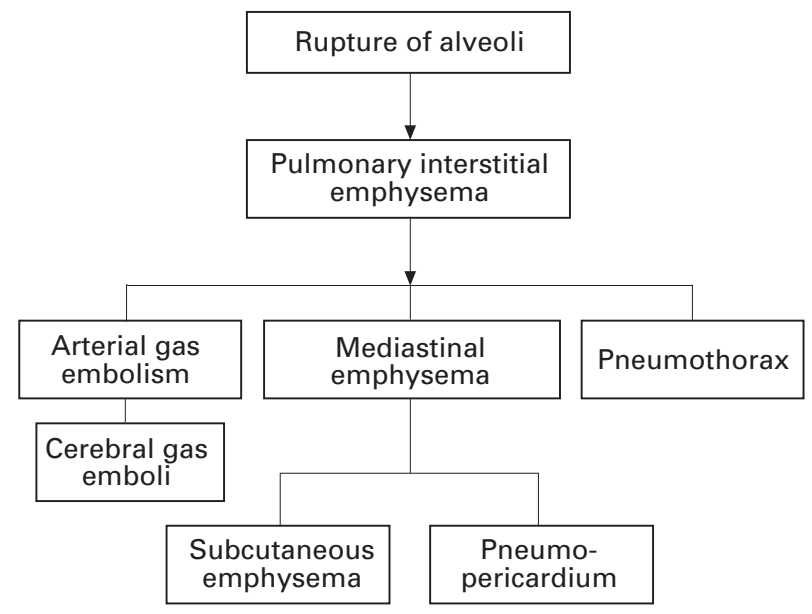

Figure 1 Consequences of pulmonary barotrauma.

particularly into the carotid arteries. These pathogenetic steps were elucidated by animal experiments in the late $1950 \mathrm{~s}^{38}$ and by necropsy findings and experimental observations in cadavers.

The complication of cerebral arterial gas embolism can be fatal, but in its absence PBT may be only a minor problem. It may present with haemoptysis, chest discomfort, mediastinal emphysema, or pneumothorax (fig 1). With continued ascent a simple pneumothorax may, however, become a life threatening tension pneumothorax. Symptoms of arterial gas embolism include unconsciousness, motor weakness or paralysis, somatosensory changes, visual disturbance, vertigo or headache ${ }^{10}$ The highest risk of PBT occurs near the surface where the rate of gas expansion is greatest (a doubling of trapped air volume from a depth of $10 \mathrm{~m}$ doubling of trapped air volume from a depth of $10 \mathrm{~m}$
to the surface, but progressively lesser increases over $10 \mathrm{~m}$ ascents from greater depths)

DECOMPRESSION SICKNESS

During diving the tissues are loaded according to the increased ambient pressure with the inspired gases oxygen and nitrogen. Since nitrogen is not metabolised its content in the tissues increases in proportion to the ambient pressure. When the diver ascends the ambient pressure decreases. When the sum of the gas tensions in the tissue exceeds the ambient pressure supersaturation occurs. Under these conditions gas freed from the tissue forms bubbles which may rupture cell membranes and obstruct vessels leading to organ dysfunction.

DCS can be classified according to the organ or tissue affected. ${ }^{1}$ Furthermore, in order to differentiate cases according to prognosis and for standardisation of therapy, DCS type I (mild) and type II (serious) may be distinguished (box 1).

DIFFERENTIAL DIAGNOSIS

It is not unusual that the differential diagnosis between PBT with arterial gas embolism and DCS type II causes significant problems. Contrasting the characteristic features between these two disorders tends to simplify the situation (table 1). ${ }^{511}$ Fortunately the same treatmentthat is, recompression with intermittent breathing of $100 \%$ oxygen - may be effective for both types of complication. ${ }^{11}$

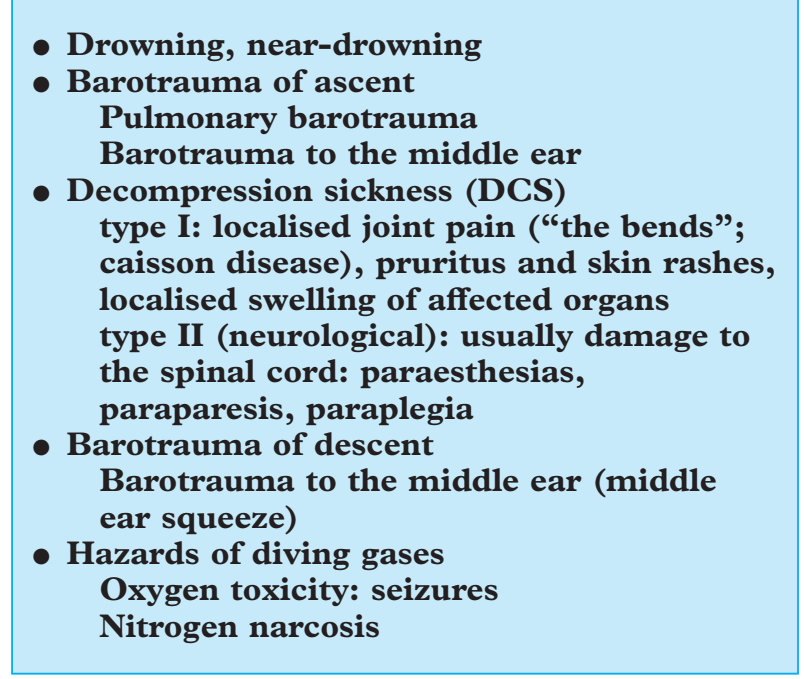

Box 1 Diving related medical problems.

Prevention of diving related complication

Dive profiles may influence the likelihood of DCS. The deeper the dive and the more decompressions required, the higher the incidence of decompression sickness. Repeated dives or flying within a certain time after diving may also be a source of difficulty since, after a dive, considerable quantities of nitrogen may remain in the tissues. Furthermore, a number of physiological and environmental factors are believed to increase the likelihood or severity of DCS. Most of these influence the blood supply to tissues and therefore the speed of gas uptake or release. Such factors consist of exercise, low water temperature, female gender, and obesity. The risk for DCS can be reduced if the rate of ascent is controlled by intermittent stops according to decompression tables, considering the above mentioned cofactors. Although rapid decompression will predispose to DCS, most divers who develop DCS have apparently complied with the decompression tables.

\begin{tabular}{|c|c|c|}
\hline & $\begin{array}{l}\text { Decompression sickness } \\
\text { type II }\end{array}$ & $\begin{array}{l}\text { Arterial gas } \\
\text { embolism }\end{array}$ \\
\hline Diving profile & $\begin{array}{l}\text { Diver's time at depth } \\
\text { exceeds the maximum } \\
\text { allowed time according } \\
\text { to commonly used } \\
\text { diving tables }\end{array}$ & $\begin{array}{l}\text { Panic or breath } \\
\text { holding during } \\
\text { ascent } \\
\text { Can occur at any } \\
\text { depths } \\
\text { Exposure }<< \\
\text { allowable time }\end{array}$ \\
\hline $\begin{array}{l}\text { Neurological } \\
\text { site }\end{array}$ & Particularly spinal cord & Primarily cerebral \\
\hline $\begin{array}{l}\text { Neurological } \\
\text { symptoms }\end{array}$ & $\begin{array}{l}\text { Progressive sensory } \\
\text { and/or motor loss of } \\
\text { the limbs } \\
\text { Paraparesis } \\
\text { Symptoms spread from } \\
\text { distal to proximal }\end{array}$ & $\begin{array}{l}\text { Unconsciousness } \\
\text { Paralysis (hemiplegia) } \\
\text { Visual disturbance } \\
\text { Headache }\end{array}$ \\
\hline $\begin{array}{l}\text { Accompanying } \\
\text { symptoms and } \\
\text { signs }\end{array}$ & & $\begin{array}{l}\text { Other evidence of } \\
\text { pulmonary } \\
\text { barotrauma (e.g. } \\
\text { chest pain, } \\
\text { haemoptysis, } \\
\text { pneumomediastinum, } \\
\text { pneumothorax) }\end{array}$ \\
\hline Occurrence & $\begin{array}{l}50 \%<1 \text { hour after the } \\
\text { dive } \\
90 \%<6 \text { hours after the } \\
\text { dive }\end{array}$ & $\begin{array}{l}\text { Within }<10 \text { minutes } \\
\text { after the dive }\end{array}$ \\
\hline
\end{tabular}


Most PBT events with arterial gas embolism are caused by breath holding and/or a rapid or uncontrolled ascent in the water. The first observations illuminating a causal sequence between PBT and arterial gas embolism were made in fatal outcomes of military personnel during submarine escape training in the $1930 \mathrm{~s}{ }^{12}$ Escape training is performed in a water filled tower with a height of around $30 \mathrm{~m}$. Access to the tower is by means of air around $30 \mathrm{~m}$. Access to the tower is by means of air
locks at various levels. The subjects are instructed not to hold their breath during the ascent but to exhale at a rate adequate to prevent overpressure in the lungs, without too great a loss of buoyancy. It is conceivable that this delicate manoeuvre may fail, resulting in the development of a markedly positive instantaneous intrathoracic pressure relative to ambient pressure. This will cause PBT with leakage of air from one or more airspaces into the pulmonary parenchyma/interstitium or pleural space. Although such events have been reported not uncommonly in the more distant past, ${ }^{121}$ recent experience during a five year period in a single centre led to only seven cases in 67000 ascents, and only one fatal outcome. ${ }^{14}$

Predicting the risk for pulmonary barotrauma From a pathogenic point of view it is reasonable to assume that certain lung diseases will exert an importan influence on the risk for PBT. Most relevant will be diseases where abnormalities of pulmonary mechanics are characterised by a broad distribution of different regional time constants-for example, diseases of the airways with regional differences in the degree of obairways with regional differences in the degree of obstruction and parenchymal diseases
differences in the level of compliance.

differences in the level of compliance.
Several groups have reported incidents of PBT which covered the entire spectrum from mere discomfort due to minor degrees of mediastinal emphysema or pneumothorax, or both, to life threatening or fatal arterial gas embolism. ${ }^{15}$ The authors usefully scrutinised these events for possible predisposing risk factors such as morphological or functional pulmonary abnormal-

Lung cysts have been observed in subjects undergoing submarine escape training ${ }^{121317-19}$ and in tunnel labourers working under pressure ${ }^{20}$ who developed PBT with and without arterial gas embolism. In a series of 55 fatal underwater accidents involving professional 55 fatal underwater accidents involving professiona divers Calder ${ }^{9}$ found 13 cases in which he could identify
lung damage as the primary cause of death. In three of lung damage as the primary cause of death. In three of four cases in which the primary cause of death was pneumothorax, bullae were present on the surface of the lungs. Another series described nine cases of PBT occurring in divers during various in-water activities, even at the surface, with or without equipment malfunction. ${ }^{16}$ Bullae, presumably pre-existing, were found in two.

These observations are interesting, yet several caveats are in order while interpreting the published findings. Since pre-dive chest radiographs were available in only very few of the reported cases, ${ }^{18}$ it might be argued that in at least some of the divers the observed abnormalities might have been a con of the diving accidents. On the other hand, relevant pulmonary abnormalities detected subsequently from CT scans might have been missed on plain chest radiographs taken before the incident, since the sensitivity of a CT scan to detect morphological abnormalities is far superior. Moreover, considerable bias may have been introduced by the publication of single case records and small case series since a control population of divers differing from the index cases only by the absence of PBT is not available.

These reservations apply also to the attempts which have been made to detect abnormalities of lung function as risk indicators for PBT. Most divers who have survived PBT had no previous lung function tests. Furthermore, lung function may differ between divers and non-diver controls, irrespective of diving accidents. For example, a Norwegian study found significantly lower values for forced expired volume in one second $\left(\mathrm{FEV}_{1}\right)$, $\mathrm{FEV}_{1}$ /forced vital capacity (FVC) ratio, and maximal flow rates at low lung volumes in a group of 152 professional divers compared with a matched non-diver control group of 106 subjects ${ }^{21}$ In most papers repored st papers reported Detailed analysis of the expiratory flow-volume loop, which may provide important information for the assessment of obstructive lung disease, has rarely been used.

\section{Introductory article}

The introductory article by Tetzlaff and colleagues ${ }^{22}$ consequently makes a valuable contribution to resolving some of these uncertainties about the potential risk factors for the development of PBT. They studied 15 patients referred to their centre with PBT and compared them with 15 patients who suffered type II (neurological) DCS without PBT. The two groups did not differ in respect to age or smoking habits. The diagnosis of either PBT or DCS was made in accordance with established criteria based on history and clinical findings. ${ }^{410}$ In all patients a pre- and post-injury lung function test was available, and all patients additionally underwent postinjury chest radiography. Pre-injury chest radiographs were available for 10 of the PBT patients (taken 5-12 months before the accident) and these revealed no abnormalities. Twelve patients with PBT and four with DCS also had a chest CT scan following the injury.

Four patients in the PBT group had reported prior lung disease (two asthma, two chest surgery in early childhood) compared with none in the DCS group. All patients in both groups had normal lung function values with respect to slow inspiratory and forced expiratory vital capacity as well as $\mathrm{FEV}_{1}$. However, analysis of preinjury lung function parameters revealed a significant The $\left(\mathrm{MEF}_{50}, \mathrm{MEF}_{25}\right)$. The mean (SD) values expressed as $\%$ predicted were, respectively, 87.5 (23.3) vs 113.1 (36.7) for $\mathrm{MEF}_{50}$ and 78.5 (28.5) vs 112.8 (44.4) for $\mathrm{MEF}_{25}$.

Chest radiographs taken following the injury showed abnormalities in five of the 15 cases of PBT (two pneumothorax, two atelectasis, one pneumopneumothorax, two atelectasis, one pneumomediastinum), all of which may have been effects rather
than causes of PBT, whereas the radiographs were all normal in the patients with DCS. Chest CT scanning revealed lung cysts in five of the 12 cases of PBT, none of which were detected on the plain chest radiographs, but there were no abnormalities in the four cases of DCS.

The authors concluded that flow-volume curves (and measurements of flow at low lung volumes) could identify diving candidates who are at increased risk for PBT. Furthermore, they proposed that a CT scan of the chest should be performed in the routine investigation of diving related PBT

These observations are interesting, but the recommendations are premature. The study was retrospective in nature and comprised a relatively small 
number of patients. No definitive recommendations can be justified with regard to screening sport divers with no history of previous lung disease until there is predictive information concerning the value of these tests. Even in patients with a history of bronchial asthma, which is the most prevalent lung disease in a young population, inferences concerning fitness to dive remain coninferences conctial.

In order to obtain conclusive answers on the risk of a particular lung disease for the development of PBT and eventually arterial gas embolism, it would be necessary to perform experimental studies. The outcome of completely healthy persons compared with those with fully characterised functional or morphological abnormalities ought to be observed after dives with comnormalities ought to be observed after dives with com-
parable profiles. Such investigations are necessarily parable profiles. Such investigations are necessarily
precluded by ethical considerations. ${ }^{914171820}$ Physicians precluded by ethical considerations. ${ }^{914171820}$ Physicians
therefore have to base their recommendations on observational studies, a format notorious for low levels of objective evidence. This unsatisfactory situation is relatively common in diving medicine for obvious reasons and explains why numerous topics remain conthe field.

No controlled clinical data are available to allow definitive conclusions about the risk of underwater diving in patients with lung diseases, particularly in patients with a history of asthma. Hence, the recommendation are based on physiological and physical inferences and on clinical information that is mostly anecdotal ${ }^{24252829}$ Asthma is, nevertheless, the most common respiratory disorder of young people wishing to undertake recreational or professional diving, and so I shall complete creational or professional diving, and so I shall complete
this review by considering the particular problems posed by asthma.

\section{Diving and bronchial asthma}

It is commonly agreed that symptomatic asthma is a contraindication to diving because asthmatics may become limited in their exercise capacity and because maldistribution of ventilation and air trapping due to uneven bronchoconstriction and mucus plugging predispose to barotrauma of ascent. However, there is no unanimity about whether somebody with asymptomatic asthma - that is, asthma which is controlled fully by medication or is The level of airway responsiveness, the underlying pathogenic basis of asthma, is distributed unimodally in the population at large, and so there is a "grey" area of considerable extent over which both patients and physicians will vary in recognising whether or not there is significant disease.

In a screening study in the consumer publication Skin Diver Magazine (circulation over 200 000) 10422 responses to the question "have you ever had asthma" were returned from readers of the magazine; $870(8.3 \%)$ were returned from readers of the magazine; $870(8.3 \%)$
answered yes, $343(3.3 \%)$ indicated that they currently had asthma, and $276(2.6 \%)$ stated that they had dived with asthma. ${ }^{26}$ In another survey 1745 newly certified divers were asked whether they had asthma and 33 of the 405 respondents (9\%) stated that they did. $^{30}$ In an additional survey of 1000 divers 36 of the 674 respondents $(5 \%)$ stated that they had asthma. ${ }^{31}$ These surveys indicate that in practice asthmatics do parsurveys indicate
ticipate in diving.

In the magazine Diver, which has a circulation of
tipate in 38000 , an anonymous questionnaire for divers with asthma was included. ${ }^{23}$ Replies were received from 104 divers $(0.27 \%) ; 89$ gave a history of asthma since childhood, 70 reported wheeze less than 12 times a year, and 22 reported wheeze daily. None of them reported a history of PBT. The authors concluded that the British Sub-Aqua Club recommendations to divers not to dive within 48 hours of wheezing seems safe.

Corson $e t a l^{27}$ made a retrospective review of DAN (diver alert network) data covering the four years from 1987 to 1990 . A total of 1213 cases of diving related problems had been reported, of which 196 had suffered arterial gas embolism and 755 type II DCS. In this accident group there were 54 divers who had a history of asthma, of whom 25 were currently asthmatic. Sixteen divers with arterial gas embolism had a history of asthma, of whom seven were currently asthmatic. Thirty divers with type II DCS had asthma, 16 of whom were currently asthmatic. In order to obtain a control population 1000 questionnaires were sent out to a randomly selected group of DAN members and 696 were returned. Of these control individuals 37 divers admitted to having a history of asthma of whom 13 were currently asthdo compare the probability of arterial gas embolism and DCS type II in a diver with asthma with that in a diver without asthma. No significant increase in the risk for type II DCS in asthmatic subjects was found. There was a nearly two-fold increase in risk for arterial gas embolism in asthmatics, but the data did not reach statistical significance. The odds ratio (with $95 \%$ confidence intervals) for all asthmatics was $1.58(0.80$ to 2.99$)$ and tervals) for all asthmatics was $1.58(0.80$ to 2.99$)$ and
for current asthmatics 1.98 ( 0.65 to 5.33$)$. Overall, the incremental risk of arterial gas embolism in this sample of diving asthmatic subjects seemed small.

It is generally agreed that symptomatic asthma is a contraindication to diving because of limitation in exercise capacity and because uneven bronchoconstriction and mucus in the airways may trap air distally and lead to barotrauma of ascent. However, there is no unanimity about when or whether someone with asymptomatic asthma should dive, and there is wide variability among asthmatics with measured airway obstruction as to whether there are perceived symptoms.

A conservative recommendation is that any person with asthma who experiences frequent exacerbations or continuously needs medication to control symptoms should refrain from diving, and that intending divers with a past history of asthma and asthmatic symptoms within the previous five years should be advised not to dive. ${ }^{24}$ However, in a recently published paper which reviewed the theoretical issues underlying this advice, and which critically examined relevant accident data, the authors concluded that “... available data suggest asthmatic patients with normal airway function at rest, and with little airway reactivity in response to exercise or cold air inhalation, have a risk of pulmonary barotrauma similar to that of normal subjects". ${ }^{25}$ Furthermore, the consensus from international experts in diving medicine is that the emphasis should shift away from ancine from an exclusionary view to one that is focused on quantifying "function".

No data are available which support routine screening of intending recreational divers by spirometry or chest radiography. It seems reasonably satisfactory to obtain a comprehensive history (and perhaps a confirmatory signature). Every person with a history suggestive of asthma or chronic bronchitis should then undergo pulmonary function tests including a flow-volume curve. Intending divers with a past history of chest trauma, chest surgery, or major chest infection should have a chest radiograph taken, recognising that its sensitivity is limited compared with a CT scan. The presence 
LEARNING POINTS

* The most common causes of diving fatality are drowning and arterial gas embolism from pulmonary barotrauma of ascent.

* Less common effects of pulmonary barotrauma are mediastinal emphysema and pneumothorax.

* It is not always possible to discriminate diagnostically between arterial gas embolism to the brain as a consequence of pulmonary barotrauma and type II decompression sickness affecting the spinal cord.

* Subjects with current airway obstruction or structural abnormalities of the lung parenchyma such as lung cysts or bullae are likely to be at increased risk from PBT and should be advised not to dive.

* Subjects with a history of asthma who are without symptoms during the previous few years and have normal lung function (including a normal expiratory flow volume curve) should not be prohibited from diving.

of cysts, bullae, or other structural abnormalities are believed to be a definitive contraindication to diving.

1 Melamed Y, Shupak A, Bitterman H. Medical problems associated with underwater diving. $N$ Engl F Med 1992;326:30

Malhotra MS, Wright HC. Arterial air embolism during decompression and its prevention. Proc $R$ Soc Med 1960;154:418-27.
Kizer KW. Dysbaric cerebral air embolism in Hawai. Ann Emerg Med 1987;16:535-41.
Dick APK, Massey EW. Neurologic presentation of decompression sickness and air embolism in sport divers. Neurology 1985;35:667-71. plongee. Etude radiologique. $\mathcal{F}$ Radiol 1989;70:357-63. Harker CP, Neumann TS, Olson LK, et al. The roentgenographic
findings associated with air embolism in sport scuba divers. $尹$ Emerg findings associated with air embolism in sport scuba divers. $\mathcal{F}$ Emerg Schaefer KE, McNulty WP, Carey C, et al. Mechanisms in development of interstitial emphysema and air embolism on decompression from depth. Fppl Physiol 1958;13:15-29.

observations on factors leading

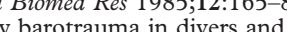

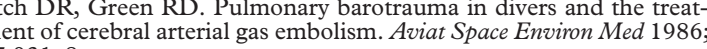

Moones. Aviatffield PJ. Guidelines for treatment
illness. Aviat Space Environ Med 1997;68:234-43.

2 Polak B, Adams $\mathrm{H}$. Traumatic air embolism in submarine escap

3 Liebow AA, Stark JE, Vogel J, et al. Intrapulmonary air trapping in
submarine escape training casualities. Armed Forces Med $\Im$ 1959;10:

14 Collins JJ. An unusual case of air embolism precipitated by de-

15 Leitch DR, Green RD. Recurrent pulmonary barotrauma. Aviat Space
16 Raymond LW. Pulmonary barotrauma and related events in divers. Raymond LW. Pulmonary
Chest 1995;107:1648-52.

17 Saywell WR. Submarine escape training, lung cysts and tension pneumothorax. Br f Radiol 1989;62:276-8.
Mellem H, Emhjellen S, Horgen O. Pulmonary barotrauma and arterial gas embolism caused by an emphysematous bulla in a scuba diver. Aviat Space Environ Med 1990;61:559-62.

19 Broome CR, Jarvis LJ, Clark RJ. Pulmonary barotrauma in submarine 20 Golding C, Griffiths P, Hempleman HV, during construction of the Dartford tunnel. Br f Ind Med 1960;17 Thoren

E Segadal K, Kambestad B, et al. Diver's lung function: small airways disease? $\mathrm{Br} \mathcal{F}$ Ind Med 1990;47:519-23.
22 Tetzlaff K, Reuter M, Leplow B, et al. Risk factors for pulmonary

23 Farrell PJS, Glanvill P. Diving practices of scuba divers with asthma.

24 Jenkins C, Anderson SD, Wong R, et al. Compressed air diving and respiratory disease. A discussion document of the Thoracic Society 25 Neumann TS, Bove AA, O'Connor RD, et al. Asthma and diving. An 26 Bove AA, Neumann TS, Kelsen SG, et al. Observations on asthma in 26 Bove AA, Neumann TS, Kelsen SG, et al. Observations on asthma in
the recreational diving population. Biomed Res 1992;19(Suppl):18.
27 Corson KS, Dovenbarger JA, Moon RE, et al. Risk assessment of asthma for decompression ilhess. Biomed Res 1991,18(Suppl):16-7. Medical assessment of fitness to dive. Surrey, UK: Bi.modical Sem, ed.

1995: 114-5.
29 Denison DM. Lung function testing of divers. In: Elliot D, ed. Medical
assessment of fitness to dive. Surrey, UK. Biomedical Seminars, 1995 . 123-33. Neumann TS, Powers AT, Osborne DE. The prevalence of asthma,
diabetes and epilepsy in a population of divers. Undersea Biomed Res Boettger ML. SCUBA diving emergencies: pulmonary over pressure
accidents and decompression sickness. Ann Emerg Med 1983;12: 